\title{
Technical and Economic Contributions in the Field Of Monitoring and Reducing the Impact of the Oil and Gas Industry on the Environmental Factors
}

\author{
Mădălina Albu ${ }^{1, a}$ \\ ${ }^{1}$ Faculty of Economic Sciences, Petroleum-Gas University of Ploieşti, Romania \\ amalbu@upg-ploiesti.ro
}

Keywords: environmental impact, pollution, oil industry, monitoring program

\begin{abstract}
Like any other industrial activity, the production of hydrocarbons affects the environment both through the performance of actual technological process and through undesired accidents, which may occur.

The paper presents technical and economic contributions in the field of monitoring and reducing the ecological impact of petroleum exploitation on the environment and an analysis of technologies used to remove pollution from soils and the subsurface contaminated by hydrocarbons. The first part presents the stream of drilling and production activities and the impact of oil and gas reservoir exploitation on the environment. Also, an assessment of pollution sources and oil industry specific agents is performed.

The case study is performed based on the documentation prepared by PETROM S.A., a member of OMV Group, in connection with Moinesti Operating Area, which includes the investigation performed in Cucuieţi structure and on the samples taken from the area and investigates in the specialized laboratories the Oil and Gas University in Ploieşti.

In the last part of this paper, the most important conclusions are presented. They outline the strengths and different issues relating to pollution removal technologies that were presented, but also the results of the performed studies.
\end{abstract}

\section{Introduction}

The main activity carried out in the scaffold consists oil and gas deposits under exploitation, collection, separation phases (oil, water reservoir, gas), oil treating, storing and sending them to users.

The mixture of oil, water reservoir and associated gas is extracted through wells operating, the mixture is routed through pipes to parks mixture of separators.

The probe is made from the surface using special equipment - drilling rigs. Own construction itself (probe) make communication between the surface layer and productive.

Construction probe depths develop from tens to thousands of meters. Putting on a challenge seeks probe of layer fluid flow through the probe to the surface for their recovery.

Since coming out of the probe and to the consumer, crude oil passes through several installations where multiple processes occur.

The technology and equipment used are not potential sources of pollution of the environment in compliance with operating parameters and monitoring current technical condition of the objectives.

The choice of method of putting into production and operation process of the probe depends on the following factors:

- Layer fluid pressure;

- Collecting the physical characteristics of the rock and fluids contained therein;

- Degree of consolidation rock strata;

- The opening of the productive layer;

- Putting into production equipment.

Operating depth varies for each deposit. After the business functionality probes can be: 
- active wells (production);

- economic well off;

- wells off the RK;

- probes calamity;

- abandoned wells;

- breakable wells;

- probes scrapped.

\section{Environmental Impacts of the Oil industry. Assessment of pollution sources and pollutants specific oil industry}

Behavior of liquid in contact with the pollutant ground - underground - underground water is very complex because it depends on a large number of variables, which basically cannot be known with certainty. Velocity of liquid pollutant vertical or lateral direction is dependent on the pollutant characteristics (composition, density, viscosity, polarity, etc.) and ground system features basement - groundwater (soil composition, soil structure, moisture, etc.).

Knowledge of the characteristics and their variations in space and time is very difficult and very expensive, due to the number and complexity of the analyzes assumed. In this situation, a compromise between cost determinations, the volume and quality of information obtained, it is very difficult.

Rating system ground - underground - underground water layer thickness is achieved by setting specific to the first impermeable layer and the analysis parameters that influence pollutant dispersion characteristics.

In a scaffold oil major sources of pollution and associated specific agents are:

○ Drilling wells: drilling fluids; detritus resulting from drilling; subsidence of land, roads; use and spread of chemicals; oil used as a lubricant and / or fuel, noise, vibration, etc. rash free;

- Probes tested production: land subsidence; possible emissions to the atmosphere and / or fluid from the well into the soil (oil, water, salt, and the oil extracted with a percentage which may reach very high, sometimes more than $90 \%$ of gas and light ends) results in production samples; discharges killing fluids; sludge etc.;

- Probes in repairs: fluid movement and killing; other fluids from the well;

- Production wells: fluid leaking into the environment of the probe (resulting from the exploitation of oil wells, condensate, gasoline, paraffin residues); emission gases produced light hydrocarbons, aromatic hydrocarbons, which are released into the atmosphere; spreading of sludge and/or substances and materials that are running operations stimulation, injection, building sands, hydraulic fracturing and acidification and so on;

- Injection wells: injection agent (salt water, waste water, gas), the infestation can occur at the surface and / or depth by breaking columns by cracking sanitation and so on;

- Pipes: phenomena of corrosion, cracking, breakage, deformation, etc. The pipes may be damaged by negligent operation of mechanical equipment (bulldozers and excavators) due to landslides, erosion, earthquakes; extreme weather conditions effects (hurricanes, storms, etc.)

- Parks tabs and receptacles: Spill may be caused by leakage and / or negligence, resulting sludge from cleaning tanks, separators, decanters, storage shores, emissions into the atmosphere and so on;

- Pumping stations, treatment and injection: substances used, in particular, for the treatment of waste water oil and for the treatment probe, the treatment depth and the installation area and so on; according to which it conveys the main agent may cause a negative impact in phase, due to possible breakage, leakage, stops, wear of the moving parts, and because of discharges used to treat oil and / or water; 
- Waste water treatment plants and/or industrial liquid spills can cause inadmissible parameters;

- Industrial areas and utilities environmental factors affecting the landscape, noise, waste disposal specific activity;

- Access roads: require removal from service of agricultural land, forestry etc., which remain affected by objective, while it is running.

The oil sector in Romania comprises a large number of industrial plants and facilities that reflect the complexity and length of underground geological industry. Tectonic complexity led to more than 450 oil fields and 150 gas deposits.

Most work in pumping oil wells and flow rates are quite low. Impurities are around $80 \%$ and the main product of the residual salt water, most of it is discharged through the re-injection.

There are also more than $14,000 \mathrm{~km}$ of pipelines for transport, and their average number of burglaries stands at around 16,000 per year.

Complexity of the oil extraction makes wide range of pollution sources to include in addition to sources of pollution from human activities, and specific pollution sources, whereas the latter have the largest share, and the effect of infestation has lasting negative impact on the environment.

The sources of pollution of the petroleum industry, both the systematic and the accidental spread have a greater or lesser extent, depending on the size of the reservoir, the type and composition of the fluid extracted, extraction technology is used, the length of the operation oil into the area, network topography and basin.

\section{Case Study-Environmental Impact Assessment Product Hydrocarbon Reservoir Exploitation Cucuieţi}

The presence of hydrocarbons in the Oligocene Cucuieţi was highlighted in 1948, but their industrial exploitation started in 1956 by wells drilled in the southern flank of the structure.

By reference to the study (01/10/2013) Cucuieţi structure was dug 43 wells, and eight wells are currently in production.

On the future exploitation of the hydrocarbon structure Cucuieţi the technical and economic analyzes performed periodically proposed application version including the continued exploitation wells and reopening current number of approximately seven wells. It should be noted that the reopening of the 7 wells will be by repair works, works that do not involve a significant impact on the environment in the area.

In the studied structure is a directly productive activity, which includes:

- Actual extraction (oil, water reservoir and associated gas);

- Internal transport probes park separators and tanks Pădurăreni 395;

- Separation and collect associated gas;

- Transport of liquid phase to deposit one Stăneşti and further to the central warehouse Albotesti;

Simultaneously, are ongoing related support activities:

$\circ$ providing necessary heat processes;

- maintenance of installations for the production process;

- supervision of the operation of all equipment and facilities;

0 intervention and remediation in case of any malfunction.

Extracted fluids (oil, gas and produced water) can become pollutants in case of accidental release into the environment. Knowledge flows and composition of extracted fluids are useful in assessing the risk of accidental pollution control implicit in the development of their capacity.

Since coming out of the probe and to the consumer, crude oil passes through several installations where multiple processes occur, the productive unit (probe) to surrender to CONPET clean oil, company that provides transport crude oil to refineries in pipeline or rail tankers.

Mixture of liquid and gaseous hydrocarbons, accompanied by formation water and mechanical impurities - in a word crude oil - after passing through the pump head reaches the mixing lines 
separating the park. Here takes place the separation of the two phases (liquid and gas) as well as the measurement of the output of each probe (calibration) or for groups of wells. Separators and tanks park (Park 395) crude oil (mixture of oil and formation water) is directed to deposit one Stăneşti and further to the central warehouse Albotesti.

Oil separate impurities from the central warehouse Albotesti, in terms of quality requirements ( $1 \%$ impurities and $5 \mathrm{~kg}$ salt / wagon) is taught by CONPET for transport to refineries.

Natural gas production structure, the date of the study is very small (about $210 \mathrm{~m}^{3} \mathrm{~N} /$ day). This amount of gas is burned in the boiler local park 395.

Extracted fluids (oil, gas and formation water) is circulated in a closed circuit so that no fluid leaks from providing service within the emissaries that cross the area, being recorded only in cases of accidental pollution.

Term environmental impacts relate to changes that occur in the environment as a result of an action (exhaust emissions, etc.). During operation of deposit were not recorded emissions in the environment planned for fluids resulting from exploitation.

Impact on air. Atmospheric air is one of uncontrollable environmental factors as pollutants once in the air, quickly dissipates and cannot feasibly be captured for treatment. Carbon monoxide affects health causing respiratory diseases, nervous and cardiovascular. For systems serving surface structure Cucuieţi operation air emissions are the fugitive volatile hydrocarbons escaping from the joint production systems: valves, flanges, fittings, instrumentation, etc. They are insignificant gravity values recorded are much lower than the permissible limit according to applicable [7].

Heat production plants are stationary sources, continuous, low variable emission of pollutants into the atmosphere. Dispersion of emissions in the troposphere depends on:

- Horizontal movement of air, atmospheric turbulence;

- Vertical instability of air masses to the temperature and pressure decrease with height;

- Different capacities diffusion of pollutants.

The only plant producing heat in the structure Cucuieţi existing steam boiler type stationary engine is $44 \mathrm{~m}^{2}$, located in the park equipment 395. Due to the small amount of flue gas it is an insignificant impact on the atmosphere.

Impact on water. Given the composition of pollutants the vehicle in the system, their impact on surface water and groundwater in the area can occur on:

- mineralization regime characterized by indicators: TDS, chlorides, sodium, calcium, magnesium;

- regime characterized by indicators of specific toxic compounds: phenols, petroleum products, iron.

From the results it is observed that the samples fall within the limits permitted by regulations in all indicators determined [8].

In conclusion, groundwater analyzed in this study is not affected by activities within the structure Cucuieţi.

Impact on soil. The investigation consisted of visiting the area and identifying the sources and land polluted with crude oil and formation water with contaminated surfaces consideration in previous years, for which compensation is payable to land owners.

Polluted areas are located generally flat and sloping land in densely source extraction along the beam pipe routes mixture of probes parks separators and oil transport from the central warehouse parks Albotesti.

Alongside soil of oil pollution occurs saltwater causing soil of soluble salts, sometimes very strong, making it practically unproductive.

From field observations in 2013, we identified the following potential degradation phenomena environmental factors:

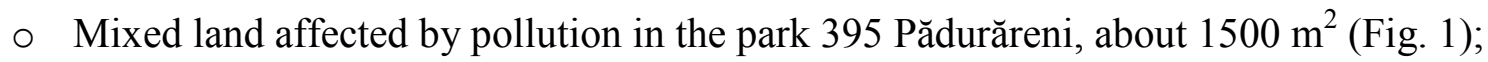




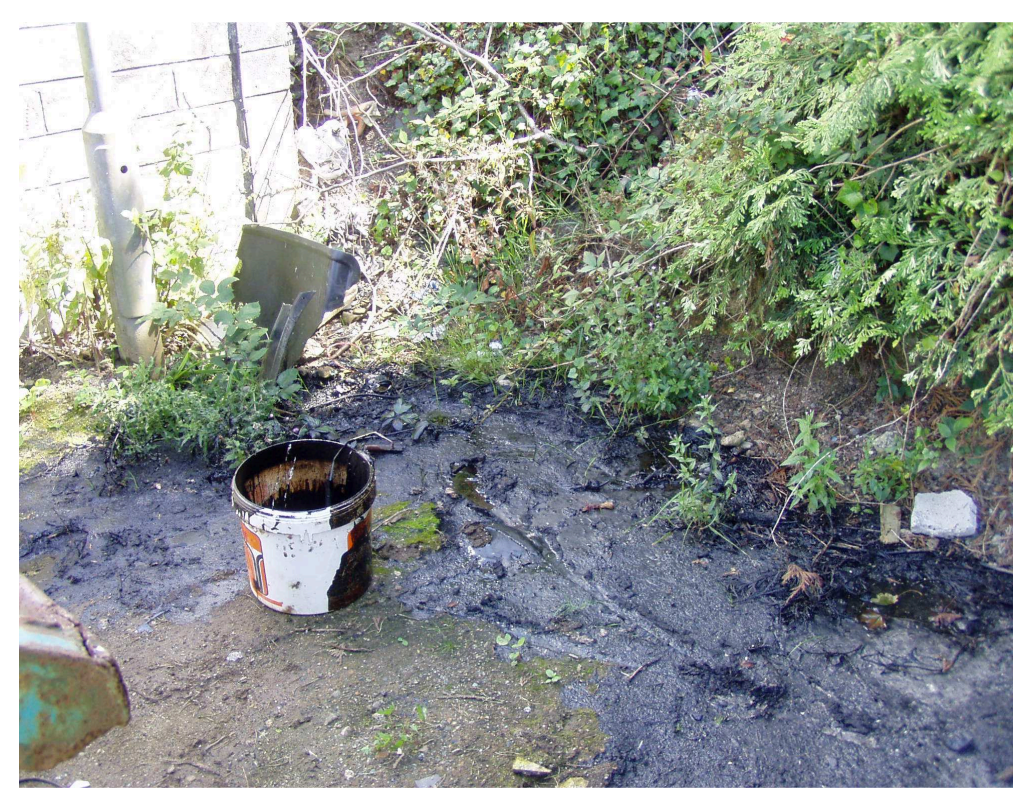

Fig. 1 Pollution in the collection and separation park 395 Pădurăreni

- Protection levees damaged tanks;

- Leaks from keyboards and pumps;

- Breaches of oil pipelines or water reservoir;

- Lands adjacent wells are contaminated with petroleum products;

- Cellars, wells, where there are not emptied rhythmically, which causes infestation areas in the immediate vicinity of the quadrate wells with oil.

To highlight the impact of soil I collected three soil samples from the exploitation of Cucuieţi (in the neighborhood park adjacent separators and wells).

In determining sampling points taken into account the following criteria:

- evidence to be near sources of pollutants;

- to assess the possibility of cumulative effects from multiple sources;

- to examine the influence of topography on the distribution of pollutants in the soil;

- be sampled and places of storage of raw materials;

- be sampled surrounding areas visibly polluted, to make a comparison (control samples).

Interpretation and assessment of soil pollution has been compared, both indicators for blank values and the values imposed by environmental legislation [1].

We executed soil profiles in the parks Cucuieţi structure and the samples analyzed in the area and Soil Science Laboratory and Ecological Reconstruction of the Faculty of Technology of Petroleum and Petrochemicals Petroleum-Gas University of Ploiesti, I watched hydrocarbon contamination chlorides and the occurrence of secondary salinization.

Analyzing versus legislative boundaries [3], two soil samples taken from the analysis, are exceeding quality indicators determined. However, comparing the values of the oil content of the control samples (S1, S2) with the control (MS), there is a certain contamination by oil products, in particular for the first sampling interval $(0-20 \mathrm{~cm})$.

To highlight the extent of soil contamination with petroleum products have plotted the concentrations determined for three soil samples compared with warning and intervention thresholds for less sensitive land use (Fig. 2).

Hydrocarbon content values for the two control samples are well below the alert thresholds (PA) or intervention (PI) for less sensitive land use. However, specific measures are necessary to limit industrial discharges of oil and water in the area. For land already affected are advised to apply different treatments to the soil to bring fertility to normal. 


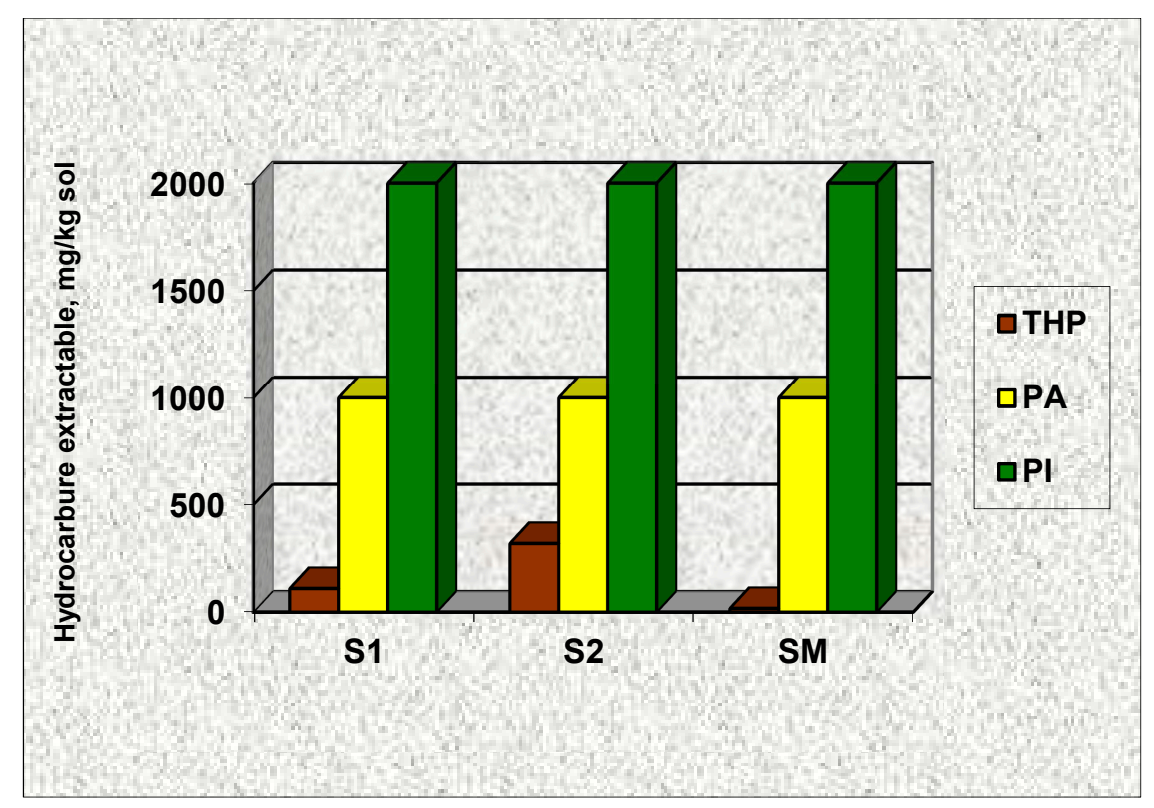

Fig. 2 The content of hydrocarbons in samples of soil $(0-20 \mathrm{~cm})$ of the Cucuieţi THP - oil content; PA - alert threshold; PI - intervention threshold

In general, soil remediation technologies consist of physical and chemical treatments on soil profile in order to promote and accelerate the process of biodegradation of petroleum products, as well as leaching of excess salts if reservoir water pollution.

If mixed pollution (oil and water reservoir) above measures are combined with appropriate measures desalination, respectively, facilities for washing of salts in the soil profile and capture water from washing through a drainage system.

\section{Conclusions}

Conclusions on the effectiveness of the work environment safe. Environmental Impact Assessment exploitation of hydrocarbon deposits Cucuieţi structure leads to the following conclusions:

1. Operations and activities on the technological mainly fall into the following classes of environmental impact:

C3 - insignificant negative impact for about $80 \%$ of the area of operation of the Cucuieţi; $\mathrm{C} 2$ - significant negative impact on the measures and equipment available it can turn into an insignificant impact for about $20 \%$ of the area of operation of the Cucuieţi;

2. Regarded globally operating activities hydrocarbon reserves will range depending on environmental factors under consideration, the levels of impact:

N1 - unidentifiable - acts as a short-term effect reversible with rapid changes in the immediate vicinity of the source of pollution where emissions into the atmosphere; $\mathrm{N} 2$ - low - acts as long-term effect reversible and local changes in the environment.

N3 - moderate - which manifests itself as an irreversible long-term effect on small areas around the source of pollution and that can only be mitigated through specific case of accidental pollution probe fluids.

Conclusions environmental quality Cucuieţi structure. Activities and technological flows performed within the oil industry may be factors of aggression local environmental conditions and / or regional, but in relation to the contribution of other sources of pollution, hydrocarbon 
exploitation activities related contribution is relatively small in terms of ecological environmental components being even slightly.

In normal operation of installations for collection fleet-separation operating activities hydrocarbon deposits Cucuieţi structure can be significant sources of environmental pollution, but it has to systematize and modernize the fleet.

Based on the documentation obtained from Petrom SA Member of OMV Group, Moineşti operating area, the investigation carried out in the Cucuieţi and on samples taken from the area and analyzed at the Faculty of Technology of Petroleum and Petrochemicals Petroleum-Gas University Ploiesti, we found the following:

1. Environmental factor air of aggression are the main factors pollutant emissions resulting from burning natural gas plants produced heat (boiler type stationary engine), but concentrations of pollutants are very low, below the limits imposed by legislation;

2. Surface water (creek saltwater) is the main factor of aggression accidental discharges of petroleum products (oil or water reservoir). Values determined indicators point to a possible contamination of water reservoir;

3. Groundwater in the area is not affected by the operation of Cucuieţi;

4. The ground, the most affected areas are in the vicinity of the productive (park collection, separation and Pădurăreni 395 wells exploiting Cucuieţi deposit).

Proposals for reduction / elimination of environmental impact. Potential restoration of contaminated sites is an expensive and sometimes impossible, it is recommended to prevent pollution and, if it occurred, to limit its effect immediate local actions.

Following this study, it is considered appropriate follow further impact polluted areas through a monitoring program of environmental factors, shown in Table 1

Monitoring involves:

- Establishing points tracking / measuring environmental factors;

- Taking and analyzing samples with a certain frequency;

- Comparing the results with the limits of normative and recording overruns;

- Trace the source of pollution.

Table 1 Monitoring program of environmental factors

\begin{tabular}{|l|l|l|}
\hline $\begin{array}{c}\text { The environmental } \\
\text { factor }\end{array}$ & \multicolumn{1}{|c|}{ Range tracking } & Pollution Mitigation \\
\hline Air & bi-monthly & $\begin{array}{l}\text { Limitation of pollutant } \\
\text { emissions }\end{array}$ \\
\hline $\begin{array}{l}\text { Groundwater and } \\
\text { surface water }\end{array}$ & bi-monthly & $\begin{array}{l}\text { Identification, source } \\
\text { elimination }\end{array}$ \\
\hline Ground & $\begin{array}{l}\text { bi-monthly }- \text { the } \\
\text { occurrence of an } \\
\text { event pollutant }\end{array}$ & $\begin{array}{l}\text { Disposal / treatment of } \\
\text { contaminated soil }\end{array}$ \\
\hline
\end{tabular}

Given the situation on the damage caused by environmental factors perimeter exploitation of the hydrocarbon Cucuieţi structure is proposed also the following: 
- surveillance of potential pollution sources and quantification of pollutants produced events and intervention measures / remedial action taken;

- implementation of effective measures to check routes or transport pipes mixture (oil or water injection);

- fleet modernization and systematization 395 Pădurăreni collection, separation and deposits;

- limiting oil leaks from 395 park or work intervention and work over through appropriate technical and organizational measures.

\section{References}

[1] Albu, Mădălina, Contribuţii tehnico economice privind activitatea de monitorizare şi reducere a impactului industriei extractive de petrol şi gaze asupra factorilor de mediu, (Technical and Economic Contributions in the Field of Monitoring and Reducing the Impact of the Oil and Gas Industry on the Environmental Factors), PhD Thesis, 2007.

[2] Albu, Mădălina, Integration of the environmental component in oil companies strategy, Proceedings of the International Conference "Sustainable Energy Use and Management", 20 may 2014, Academica Brâncuşi Publishing House, Târgu-Jiu, Romania, ISBN: 978-973-144-647-9.

[3] Buzoianu, Daniela, Strategic study on Environment Protection in the Romanian petroleum Extraction Industry, Annals of DAAAM for 2009 \& Proceedings of the 20th International DAAAM Symposium, ISBN978-3-901509-70-4, ISSN 1726-9679.

[4] Hamby, D.M., Site remediation techniques supporting environmental restoration activities: a review Department of Environmental and Industrial Health. University of Michigan, Ann.Arbor. MI 48109-2029, USA, 2001.

[5] Rocco, F., Pin, M., New Bioremediation and phytoremediation for soil decontamination: Experiences and perspectives, In: Urban Technology Network Project. Iniziativa Communitaria Interreg II C CADSES, 2000.

[6] Rojanschi, V., Bran, Florina, Politici şi strategii de medi, (Environmental policies and strategies), Editura Economică, Bucureşti, 2002.

[7] OUG nr.195/2005 Environmental.

[8] STAS 1342/91 Drinking water. 